\title{
MÚSICA AO CAMPO: \\ Uma proposta de educação \\ musical no campo
}

Sergio da Silva Pereira 
O presente artigo traz uma analise do projeto Música ao Campo, implantado no Assentamento Taquaral, Município de Corumbá-MS. Propõe uma visão crítica sobre conjuntura da Educação na Escola Municipal Rural de Ensino Fundamental e Integral Monte Azul. Indica os diálogos políticos entre a Secretaria de Educação do Município, Fundação de Cultura do Pantanal e a Comunidade Escolar, procurando fortalecendo os caminhos interdisciplinares que a música constitui na escola e os aspectos históricos da proposta de Educação Popular. Lançamos um olhar sobre a identidade camponesa e a afirmação desta, numa perspectiva de rompimento de preconceitos históricos criados por uma oligarquia política e social. Propõe a organização da comunidade escolar e ações possíveis para o fortalecimento e manutenção do projeto. As experiências com diferentes formações musicais, Orquestra do Campo, Banda de Percussão Monte Azul, Camerata do Campo, duplas de música sertaneja e banda de rock (Química e os Poetas em Chamas), são exemplos desse trabalho.

Palavras-Chave: Educação do Campo, educação musical, identidade camponesa, reforma agrária, protagonismo juvenil.

\section{INTRODUCÃO}

B

uscaremos tratar neste trabalho de temas adjacentes à educação do campo, especialmente à educação musical "do campo", olhando para uma iniciativa realizada numa escola municipal rural de ensino integral, com aproximadamente 240 alunos(as) divididos(as) entre ensino infantil e ensino fundamental, denominada Monte Azul, localizada no Assentamento Taquaral, com 398 famílias assentadas numa área de aproximadamente 10.000 habitantes, no Município de Corumbá-MS.

Traremos um olhar sobre os processos de atuação política e dialógica que a comunidade escolar desenvolveu junto ao poder público municipal, a partir da proposição da implantação do Projeto Música ao Campo, buscando parcerias com Associações e dividindo as responsabilidades com a Secretaria Municipal de Educação e a Fundação de Cultura do Pantanal . Por meio deste engajamento político, a comunidade escolar, buscava de certa forma fortalecer mecanismos que reforçassem a identidade camponesa e que possibilitassem discutir a coerção social sofrida pelo(a) jovem camponês(a) sobre os meios urbanos, buscando uma análise conceitual sobre o que é o meio "rural" em termos identitários, além de um recorte histórico da Reforma Agrária tendo o povo do Taquaral como objeto de estudo. 
A motivação maior quanto à implantação do Projeto Música ao Campo, na Escola Monte Azul, foi a necessidade de se ter práticas culturais capazes de formar sujeitos protagonistas de um campo onde a perspectiva não se daria como um ambiente apenas de produção agropecuária, mas um lugar de bem-viver, onde a música ocupa uma posição fundamental na constituição identitária camponesa. Essa missão começou na escola, neste caso, numa escola pública que está no centro de um assentamento da reforma agrária, mas não apenas numa posição geográfica, mas um centro social e político.

O lugar do ensino de música na escola, durante os primeiros anos do projeto ocorreu no contraturno escolar, atendendo os(as) alunos(as) interessados, precedendo as práticas que viriam a se tornar obrigatórias com a escola integral e durante sete anos aconteceu dessa forma. Outros lugares conquistados por esse ensino de música, foram os palcos em abertura de eventos na cidade, principalmente na UFMS(Universidade Federal do Mato Grosso do Sul) ou mesmo, na própria escola. Foram realizados concertos para a comunidade, apresentações e intervenções nas salas de aula. A música feita na escola ganhava uma importância pedagógica e artística fundamental na autoestima e na autoavaliação dos(as) alunos(as).

O fazer música de maneira artística e o estudar música estavam profundamente relacionados, pois as crianças e adolescentes se motivavam a estudar quando havia alguma apresentação marcada, com isso o grupo da Orquestra do Campo, passou a ter uma equipe de produção, formada por membros da comunidade e alunos(as) que não estavam no grupo musical como instrumentistas ou cantores(as), mas eram responsáveis pela logística, produção e promoção de eventos com finalidade de realizar concertos e buscar recursos para infraestrutura.

Este engajamento é fruto da história da escola Monte Azul, resultado de uma construção coletiva de lutas pela Reforma Agrária e pela Educação Popular, esta conceituada por Paulo Freire, como podemos ver a seguir:

A educação popular cuja posta em prática, em termos amplos, profundos e radicais, numa sociedade de classe, se constitui como um nadar contra a correnteza é exatamente a que, substantivamente democrática, jamais separa do ensino dos conteúdos o desvelamento da realidade. É a que estimula a presença organizada das classes sociais populares na luta em favor da transformação democrática da sociedade, no sentido da superação das injustiças sociais (FREIRE, 2014, p. 118). 
Em meados dos anos 80 começaram a surgir muitos movimentos sociais organizados por sindicatos, igrejas progressistas, partidos políticos, associações e cooperativas. O movimento que precede a conquista pela terra no caso do Taquaral, teve sua gênese nos sindicatos e trabalhadores rurais da Grande Dourados e municípios do sul do Estado de Mato Grosso do Sul.

O termo "Reforma Agrária" é posto no Estatuto da Terra, Lei № 4.504, DE 30 de novembro de 1964, parágrafo 1: "Considera-se Reforma Agrária o conjunto de medidas que visem a promover melhor distribuição da terra, mediante modificações no regime de sua posse e uso, a fim de atender aos princípios de justiça social e ao aumento de produtividade". A preocupação dessa lei, sancionada pelo General Castelo Branco, Presidente da República, durante a ditadura militar, é com o uso da terra e seus fins produtivos, com a manutenção da indústria e do mercado. A Lei traz um viés que representa o pensamento hegemônico de uma sociedade que está voltada à produção de matéria prima, voltada à indústria e à construção do que hoje entendemos como Agronegócio, num espaço vazio de pessoas, mas dotado de tecnologia, baseado no latifúndio e produção em largas escalas de commodity", chamada naquele momento de "Revolução verde".

Para tanto, o Campo deveria ter pessoas capacitadas para operar tais meios tecnológicos, estancar o êxodo rural até certo ponto, mantendo a mão de obra necessária para o modelo ruralista desenvolvimentista e que fosse capaz de desinchar os meios urbanos de retirantes camponeses despreparados para o mercado.

O pensamento da Escola Ruralista assim é exposto por Carvalho.

A tendência ruralista tinha por objetivo principal a fixação das pessoas no meio rural. Neste período o papel da escola era o de transformar a mentalidade dos povos do campo. Nesse sentido, Torres Filho (1944,p.185) afirma que em relação ao ensino agrícola primário "convém ir mais longe, procurando retê-lo à terra, pondose assim barreiras ao êxodo rural que, desviando dos labores do solo energias produtivas, vem agravar os centros urbanos". [...] Subjaz ao discurso ruralista que os povos do campo não estavam em sintonia com sistema social e econômico do qual a produção agropecuária era a principal riqueza do país (CARVALHO, 2016, p. 147) .

Nas décadas de 80/90, os acampamentos que se organizavam em torno da busca pela terra foram estimulados pela própria promessa do Governo Federal que pretendia assentar milhões de famílias. Segundo Moreira:

${ }^{1}$ Commodity é qualquer bem em estado bruto, gerado de origem agropecuária ou de extração mineral ou vegetal, produzido em larga escala mundial e com características físicas homogêneas, seja qual for a sua origem, destinado ao comércio exterior. BREDA p. 34 (2008). 
O Decreto $\mathrm{n}^{\circ}$ 97.766, de 10 de outubro de 1985 , instituiu o novo Plano Nacional de Reforma Agrária, com a meta de destinar 43 milhões de hectares de terra para assentar 1,4 milhão de famílias até o ano de 1989. Com o novo decreto da reforma agrária, os movimentos sociais ganharam força e mobilizaram os trabalhadores para que pressionassem o governo a fazer acontecer de fato a reforma agrária, criando centenas de acampamentos no país. (MOREIRA, 2010, p. 17).

A expansão da "Revolução verde", um modelo agrícola industrial, de crescente mecanização do campo e de políticas de financiamento que privilegiavam os grandes produtores, seus representantes políticos, não permitiram que a promessa feita pelo próprio governo fosse adiante. Portanto, como forma de pressão política, os movimentos sociais organizaram acampamentos com barracas de lona preta, que traziam arrendatários, meeiros, camponeses e camponesas, expulsos de suas colônias e áreas de produção e vida social, pela crescente mecanização do campo.

No caso do Taquaral não era diferente: famílias inteiras moravam nesses precários barracos. Junto a essa comunidade havia uma organização dividida em setores, lideranças políticas, coordenação de educação, saúde, equipes responsáveis por promover eventos culturais e de entretenimento, como místicas ${ }^{2}$, bailes e torneios esportivos. O setor da educação era responsável por viabilizar a construção coletiva de salas de aula improvisadas de pau-a-pique e cobertas por folhas de coqueiro e lona. Podemos observar um exemplo de sala de aula utilizado naquele momento histórico, lembrando que, muitas das vezes, as salas eram multisseriadas e o(a) professor(a) assumia muitas funções que costumeiramente não são realizadas nesta profissão, como as atividades de fazer a merenda ou até mesmo, construir a própria sala de aula, como podemos observar na imagem a seguir.

A equipe de educação, contava com pais e mães, educadoras e educadores que negociavam com os poderes públicos e a sociedade civil a doação de carteiras, quadros-negros e materiais didáticos básicos, além de recrutar professores, fato que de certa forma tornou a se repetir na inserção da música na escola. Alguns dos(as) professores(as) tinham estudado apenas até a quinta série ${ }^{3}$ do ensino fundamental e outros poucos tinham formação de nível médio. Realizavam um trabalho voluntário e, posteriormente, eram capacitados em projetos propostos pela Igreja Católica por meio da

\footnotetext{
${ }^{2}$ A mística é uma espécie de ritual e celebração, que acontece de diversas maneiras e com significados e sentidos variados. Essa prática é realizada nos mais variados espaços como nos acampamentos, assentamentos, em Encontros, Congressos e nas diversas manifestações que o MST organiza. Em geral é praticada em forma de teatro, contendo músicas, poesias e diversos elementos simbólicos em seu interior (COELHO, p. 327, 2011).

${ }^{3}$ Atualmente $4^{\circ}$ ano do ensino fundamental.
} 
Comissão Pastoral da Terra (CPT) e Associação de Educadores Católicos de MS (AECMS). Moreira descreve como esse processo ocorreu durante a década de 80:

Em 1985 a Comissão Pastoral da Terra (CPT) promoveu a formação de monitores voluntários para trabalhar com as comunidades rurais, pois entendia que era necessário pensar numa educação diferenciada e comprometida com o modo de vida rural e se propunha a enfrentar o desafio de criar um material didático próprio para o meio rural, partindo do meio para o todo, criando e difundindo um saber que seja específico sem negar a totalidade. A proposta utilizada nos cursos de formação de educadores do campo teve como base os ensinamentos de Paulo Freire, com sua metodologia da pedagogia libertadora, mas esse processo foi muito difícil, recorrendo, em grande parte, ao trabalho voluntário (MOREIRA, 2010, p 45).

Nesse contexto, a educação do campo parece ter sido o referencial que norteou a formação dos professores(as) do Taquaral. Entendemos algumas concepções de educação do e no campo com base nas apresentadas por Caldart:

A Educação do campo se construiu pela passagem da política produzida nos movimentos sociais para o pensar/pressionar pelo direito do conjunto dos camponeses ou dos trabalhadores do campo. Isso implicou um envolvimento mais direto com o Estado na disputa pela formulação de políticas públicas específicas para o campo, necessárias para compensar a histórica discriminação e exclusão desta população do acesso a políticas de educação, como a tantas outras (CALDART, 2009 p. 51).

A identidade camponesa e as bases formadoras da escola nortearam também o ensino de música, pois não havia possibilidade do projeto Música ao Campo estar dissociado da realidade local que comunga da mesma fonte da educação popular, portanto podemos chamar de "Educação Musical do Campo" as práticas realizadas na escola Monte Azul, a dinâmica aplicada ao projeto considerou a realidade camponesa como algo fundamental, buscando a participação democrática dos pais e comunidade escolar, trazendo uma reflexão sobre o sentido do trabalho do camponês e das lutas sociais e culturais desses grupos (MUNARIN; SHMIDT, 2016, p.18).

A Educação do Campo e a Educação Popular fundiram-se com certas linhas filosóficas, como o multiculturalismo crítico, que recusa-se a ver a cultura como não conflitiva e, portanto, harmoniosa. Propondo que a diversidade deva ser afirmada dentro de uma política de justiça social (LAZZARIN, 2006). 


\section{A ORQUESTRA DO CAMPO: IDENTIDADE E CONFLITO}

partir do ano de 2007, o Projeto Música ao Campo passa a ser re-
gular na Escola Monte Azul, atendendo crianças e adolescentes do
quarto ano à nona serie do ensino fundamental. Uma das propostas do projeto é formar um grupo capaz de executar músicas de maneira orquestrada e, para isso, iniciaram-se, então, aulas de flauta doce, escaletas, violinos, violão e percussão. Em 2010, a escola foi contemplada com um programa que forneceu instrumentos de cordas, flautas transversais e estantes para partitura e, assim, nasceu a Orquestra do Campo. Tendo um professor e uma professora, licenciados em música, trabalhando de maneira voluntária, a Orquestra começou a tomar corpo, ensaiando peças regionais, eruditas e populares. No ano de 2012 realizou mais de 20 apresentações.

Como repertório destacam-se as seguintes obras: Cio da Terra (Milton Nascimento e Chico Buarque), Hino da alegria (L.V. Beethoven 1770-1820), Asa Branca (Luiz Gonzaga 1912-1989 e Humberto Teixeira 1915-1979), A Chalana (Mario Zan 1920-2006 e Arlindo Pinto 1906-1968), Tristeza do Jeca (Angelino de Oliveira 1888-1964), Cuitelinho (Anônimo recolhido por Paulo Vanzoline e Antonio Xandó), Minueto (J.P. Krieger 1649 - 1725), Minueto em Sol (J. Sebastian Bach 1685-1750), ANDANTE em MI menor (Antonio Vivaldi 1678-1741), Suíte Carajás (Prelúdio-Interludio-Valsa da Semente-Final. Sergio Pereira) e Trenzinho do Caipira (Heitor Villa Lobos 1887-1959).

Participar da Orquestra era um orgulho para os pais e comunidade escolar. Matérias de TV e jornais divulgaram as atividades e elevaram o nome da escola dando visibilidade ao assentamento. Essas atividades fortalecerem a autoestima e a construção da identidade de ser camponês(a), acontecendo de fato uma reconfiguração deste "ser-estar-pertencer".

O grupo em suas relações interpessoais, costumeiramente realizavam trocas de saberes e descobertas no mundo da música, na afetividade, política, nas relações de gênero, adentrando assim, um universo multicultural crítico que resignifica muitos elementos identitários do mundo social e do trabalho, esses novos papéis, também produzem superposições, contradições e convergências (KLEBER, 2016, p. 216).

Outro fator importante é do assentamento Taquaral estar muito próximo à cidade de Corumbá $(5 \mathrm{~km})$, facilitando o acesso quase que diário para muitos(as)jovens, oportunizando direitos no urbano que ainda 
não foram contemplados no campo, como as políticas públicas, transporte coletivo, ensino profissionalizante, ensino médio e superior, serviços de saúde, comércio e entretenimento, criando uma lacuna que de certa forma exerce uma força coercitiva do urbano sobre o campo, apesar desta coerção, os integrantes do projeto se mostraram propensos a permanecerem no assentamento. O projeto trouxe a possibilidade deles se tornarem capazes de realizar atividades ditas refinadas, numa cultura, que a princípio, só poderia ser acessada em condições especificas, no meio urbano, com poder econômico além das possibilidades daqueles(as) jovens, vivendo e morando no campo. A escola, possui papel fundamental nesta construção identitária, porém, ela também sofre uma reformulação, em seu quadro docente, na relação com a comunidade, tendo um certo distanciamento, enfraquecendo sua ação libertária.

É notável que após o afastamento (por aposentadoria ou doença) dos educadores(as) formados(as), sob as bases epistemológicas de Paulo Freire e da Educação do Campo, tendem os demais professores(as) a seguir um modelo que tradicionalmente atende aos povos do campo, a partir de pedagogias e currículos urbanos, negando suas singularidades (CARVALHO, 2016, p. 182).

Esse fato fortalece uma ilusão sobre a cultura urbana, reforçando um dilema posto em sala de aula e se transmutando para o mundo do trabalho, pressionando de certa forma o estudante do Taquaral: "onde ser camponês(a) é ser atrasado(a), trabalhar na roça a vida toda é demasiadamente penoso". "E ser urbano é trabalhar num escritório com ar condicionado e um salário bom no final do mês, é uma realidade objetivada". Essa dualidade, muitas vezes, é reforçada na família, conforme explica Castro, citado por Wanderley:

Os identificados como jovens rurais seriam aqueles que vivenciam o que podemos denominar duplo "enquadramento". Por um lado sofrem com as imagens pejorativas sobre o mundo rural e as consequências desta desvalorização do mundo rural no espaço urbano - ou seja, a associação do imaginário sobre o "mundo rural" ao atraso e a identificação como roceiros, peões, aqueles que moram mal. Por outro lado são criticados por seus pais ou adultos em geral, por serem muito urbanos. O jovem rural carrega o peso de uma posição hierárquica de subalternidade, ou seja uma categoria percebida como inferior, nas relações de hierarquia estabelecidas na família (CASTRO, 2009 apud WANDERLEY, 2007, p.39) 
Notamos que a consciência de identidade e pertencimento camponês é mais evidente nos integrantes do projeto, em relação a outros(as) jovens que vivem a mesma realidade no campo, mas que não participaram de alguma atividade coletiva, pois enxergam mais possibilidades no campo, além de plantar ou criar animais e mesmo nessas atividades, surgem novas possibilidades por estarem em contato com Universidades, cursos, exposições. Abre-se uma gama no universo camponês, como por exemplo, a permacultura ${ }^{4} \mathrm{e}$ a agroecologia 5 . Esses(as) jovens, como sujeitos que se veem em processo de libertação, começam a entender sua comunidade como um espaço de bem viver, com uma relação próxima à natureza e alimentação saudável e hábitos mais solidários. Isso não significa que se construa uma abnegação do urbano, pois esse também é um espaço onde se pode tocar, estudar, comercializar os produtos da roça e onde o Projeto Música ao Campo em suas variadas formações, conforme veremos, é reconhecido como gerador de cultura. $\mathrm{O}$ que se percebe é uma circulação entre os dois mundos - urbano e campo - que é diferente dos mundos urbano e rural.

Os valores de pertencimento são evidentes e o projeto social na escola ajudou a reconstruir esses conceitos. Ficando clara a importância da proposta coletiva trazida, tal processo é relatado por Kleber:

Os cuidados sociais permeando os processos de aprendizagem musical emergem vários níveis de percepção pessoal. Aspectos como o estigma da cor da pele, do lugar onde moram e da origem pobre emergem dos depoimentos colados nas identidades dos alunos. Tal vivência apresenta-se como um fator muito significativo para a reconstrução de novos valores pessoais e sociais (KLEBER, 2016, p. 231).

${ }^{4}$ A palavra permacultura originou-se da expressão em inglês "permanent agriculture“, porém, hoje, devido a ampliação de sua abrangência pode-se dizer que a permacultura deriva da expressão "cultura permanente". http://permacultura.ufsc.br/o-que-e-permacultura/ ${ }_{5}^{5} \mathrm{~A}$ agroecologia é uma vertente agronômica que engloba técnicas ecológicas de cultivo com sustentabilidade social. Ela também incorpora fontes alternativas de energia e sua principal preocupação é "sistematizar todos os esforços num modelo tecnológico socialmente justo, economicamente viável e ecologicamente sustentável” (www.ambientebrasil.com.br) 


\section{O COTIDIANO DA SALA DE}

MÚSICA NA ESCOLA INTEGRAL

IMAGEM 1. OfICINA DE MÚSICA, EsCola M.R.E.F.I.

MONTE AZUL, ENSAIO DA ORQUESTRA DO CAMPO .

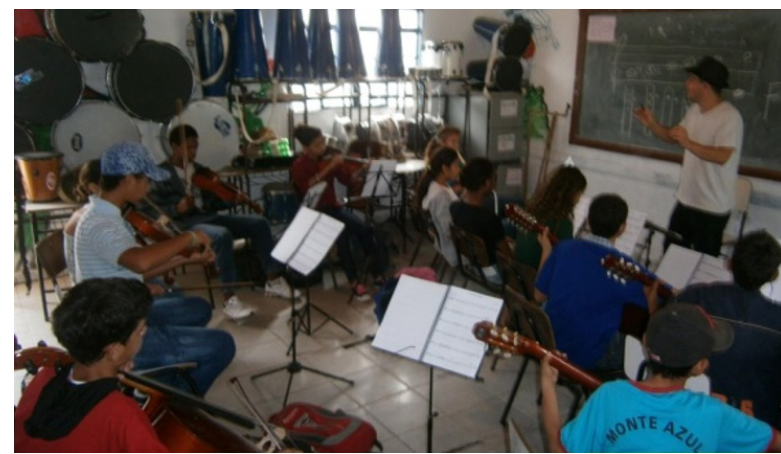

Fonte: Acervo pessoal (2010)

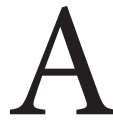

té o ano de 2014 o projeto acontecia em regime de contraturno, com 8 horas semanais para os alunos envolvidos no projeto, independentemente do instrumento que escolhiam tocar, as aulas eram coletivas e multi instrumentais, cada líder de naipe ajudava seus colegas em aspectos técnicos e o professor circulava entre a sala. Os materiais eram fornecidos pela escola e alguns alunos(as) acabavam adquirindo seus próprios instrumentos.

O ensino teórico, de leitura e divisão rítmica era aplicado concomitantemente com a prática instrumental e os temas geradores (peças e estudos) de acordo com as dificuldades técnicas que se apresentavam.

A partir de 2015, a escola aderiu ao sistema integral, ou seja, ficando 8 horas por dia e todos(as) os(as) alunos(as) permaneciam na unidade oito horas por dia. Fato este que dificultou a continuidade do processo que vinha acontecendo há sete anos, pois a participação na oficina de música sempre foi voluntária e, assim, não poderia ser uma disciplina que tivesse entre as disciplinas obrigatórias a todos(as) estudantes.

No ano de 2015 optamos por atender as turmas de pré-escolar ao terceiro ano do ensino fundamental, oferecendo aulas de musicalização infantil, obrigatórias com a carga de uma hora semanal. E turmas do quinto ao nono ano, com aulas instrumentais e teóricas, optativas. Entretanto, no caso 
das turmas de quinto ao nono ano, as aulas não obtiveram o mesmo êxito de outros anos, devido ao curto tempo de aula, pois quando se acabava de afinar os instrumentos, dividir vozes e organizar estantes e partituras, a aula terminava. Dessa forma, não foi possível realizar o concerto de final de ano em 2015.

No primeiro semestre de 2016 optou-se por dividir as aulas turmas, por naipes e idade a partir do quinto ano do ensino fundamental, a musicalização infantil, seguiu no mesmo prisma do ano anterior. Os alunos foram, inicialmente, agrupados por instrumentos: passaram a ser divididos entre violões pré-adolescentes de 9 a 12 anos e adolescentes de 13 em diante; violões, flautas doce; flautas transversais; teclados e escaletas; cordas e percussão. A divisão por idade deu-se apenas no violão por ter mais alunos interessados.

A formação dos grupos específicos, entre eles a Orquestra do Campo, Camerata, Banda de Percussão, Banda de Rock, Duplas de música caipira, se deram por desdobramentos na sala de aula, causados por motivação, afinidade, capacidade técnica, disposição para ensaios e apresentações.

A vivência musical naquele momento passou a ser mais empírica, realizada através de reprodução e imitação, sendo fundamental a participação dos monitores (ex-alunos que se tornaram voluntários e bolsistas do projeto) que serviam de modelo para os demais. Essa prática motivou de tal maneira as turmas que o estudo da técnica, passou a ser algo desafiador, mas prazeroso. Passamos a trabalhar com composições e partituras alternativas, que fossem voltadas a encadeamentos harmônicos de funções tonais, deixando as linhas melódicas mais complexas aos(às) alunos(as) com maior domínio de técnica, objetivando o fazer musical de acordo com as possibilidades de cada um.

\section{MÚSICA AO CAMPO: OS FAZERES MUSICAIS.}

Orquestra do Campo é o carro chefe do projeto que visa integrar to-
dos(as) os(as) alunos(as) interessados, numa proposta musical de-
mocrática e acolhedora, que não se preocupa a priori com a limpeza do som, afinação ou domínio técnico do instrumento, mas com o processo de construção coletiva, a improvisação e rearranjos e, a análise crítica do trabalho que estão desenvolvendo. Gravações de áudio e vídeo são realizadas para que o grupo em momentos posteriores possa assistir e refletir sobre a performance, se avalie. 
Trazendo desse modo uma avaliação positiva sobre a mudança do sistema de turno escolar, para o integral. Da transmutação se uma abordagem técnica, erudita, voltada à leitura e execução instrumental por meio de partituras tradicionais, para uma perspectiva alternativa, lúdica e empírica, se aproximando da vivência musical do aluno.

Uma experiência parecida é a relatada por Viera (2012):

Valorizando sempre as condições dos alunos, nossos objetivos centravam-se na ampliação gradual das habilidades de execução e improvisação e no desenvolvimento da imaginação musical. A pratica de "fazer musica de verdade", em grupo, produzia saberes conceituais e técnicos, competências musicais e sociais. O que nos passava, o que nos acontecia, o que nos tocava, era um misto de duas visões. A primeira, cartesiana, oriunda dos meus vícios compartimentalizantes e autoritários. E a segunda, rizomática, oriunda de uma aposta no fluxo coletivo e no prazer do fazer musical (VIEIRA, 2012, p 77).

Uma das atividades mais prazerosas que são realizadas na escola, é a fanfarra. Mesmo os(as) estudantes que não participam "da música", como eles(as) dizem, desejam tocar na fanfarra. Inferimos que esse interesse talvez possa ocorrer por ser uma atividade mais curta, que acontece sazonalmente, após as férias de julho e termina em setembro, quando acontece o desfile do aniversário do município, em 21 de setembro/09. Toda escola se enfeita com, faz carros alegóricos, comissões de frente, portas bandeiras e balizas. A fanfarra geralmente toca 4 quatro ou 5 cinco músicas de gêneros e ritmos diferentes. Em 2015 o repertório foi: O xote das meninas (Luiz Gonzaga e Zé Dantas), La Cucaracha (Folclóre Espanhol) e Guantanamera - Cancíon cubana (José Martí e Josito Fernandes), Marrequinha da lagoa (Sirirí - folclóre pantaneiro) e Levada de samba (improvisação em ritmo de samba).

A Camerata é formada por 1 violoncelista, 2 violonistas, 2 flautistas, 2 violinistas, 1 tecladista e 1 percussionista. $\mathrm{O}$ grupo se dedica tanto à música erudita quanto a popular. Também atuam na Orquestra como lideres de naipe e condutores das linhas mais complexas na grade, geralmente é formada por alunos(as) que estão cursando a nona série, ou por estudantes egressos da escola que mantém seu vínculo com o projeto, mesmo após terminarem o ensino fundamental ou o médio.

A banda Química e os Poetas em Chamas é uma vertente do projeto dedicada à música autoral e à poética que lida com questões políticas, 
românticas e sociais. Foi criada por professores, membros da comunidade escolar (ex-alunos) e integrantes da camerata. A criação da banda possibilitou a fruição de obras inéditas, de integrantes que já eram compositores e outros que se tornaram, inclusive produzindo peças musicais usadas na didática de alfabetização e composição do hino (em forma de canção sertaneja) da escola, descrevendo sua história e características sociais da comunidade.

A banda Química é formada por um baterista, 2 guitarristas, 1 baixista e 1 violonista popular. Revezando o vocal 3 integrantes. Durante o período de julho de 2015 e agosto de 2016, a banda produziu um CD de maneira independente contendo 13 faixas autorais, com a tiragem de 1100 unidades de maneira independente.

\section{CONCLUSÃO}

s variadas atividades musicais são resultado de desdobramentos que
o processo foi sofrendo durante o tempo. A princípio o projeto era
voltado à música orquestrada, fato que dificultou a adesão de muitos alunos que queriam tocar as músicas próximas à sua vivência. Portanto, as verdades absolutas de uma visão, de certa forma totalitária e acadêmica foram sendo desconstruídas a partir da observação atenta e do acesso à literatura sobre educação musical.

Podemos considerar que um dos motivos dos nossos equívocos didáticos, foi a urgência em tocar, o "mostrar serviço", para receber apoio político e assim dar continuidade ao projeto. Facultando ao grupo uma pressão inicial, desnecessária. Contudo, com o passar dos anos, com o crescente desenvolvimento dos alunos essa necessidade foi exaurida.

A primeira geração de alunos(as) (2007 - 2014) construiu a possibilidade e a garantia de um apoio permanente dos órgãos governamentais. Agora o fazer "música de verdade" é possível, com mais tranquilidade e prazer, sem a pressão do ter que ler partitura necessariamente, para ser músico e participar de um movimento.

A perspectiva da escola em sua visão progressista não poderia levar a outro caminho senão a essa reconstrução democrática e assertiva em redefinir os rumos pedagógicos.

A integralidade trouxe a garantia do espaço da música na escola Monte Azul e o despertar de um anseio em outras escolas do campo, que almejam seguir o mesmo modelo. Contudo, acabam por esbarrar na carência 
de professores(as) capacitados(as) (ou que queiram se arriscar nesta proposta) para se trabalhar com uma realidade multiseriada e instrumental.

O fato é que a escola pública de educação popular oferece uma imensa gama de possibilidades na área da educação musical e desenvolvimento de potencialidades, tanto no âmbito artístico, político, psicológico, cognitivo e social.

Defender a Educação Musical do Campo, na escola publica é fundamental, pois sua proposta prática, ultrapassa o discurso do belo, de que a música "acalma", que serve à disciplina. Podemos observar que ela (a música), vai além, fortalece a identidade, as relações do grupo, o protagonismo, a possibilidade de se ver como sujeito e se libertar de estigmas sociais e assumir um papel que por vezes é tirado do(a) jovem camponês(a), em seus direitos fundamentais de humanidade, do empoderamento do ser como sujeito.

Entendemos que a construção de propostas que se alinhem com a Educação do Campo, buscando um reconhecimento nas iniciativas pedagógicas das organizações e movimentos sociais, com sua cultura característica, sua história, práticas educativas e sociais consolidadas (CARVALHO, 2016, p. 197) nos faz acreditar que a Educação Musical do Campo, é uma realidade possível.

São necessárias mais pesquisas na área da educação musical, voltadas a este público especifico, para a partir daí fundamentar teoricamente os processos de formação de professores(as) camponeses(as) ou professores(as) que atuem com pertencimento do campo, que sigam uma visão de educação popular, democrática, estabelecendo relações entre a escola e o mundo, trazendo a comunidade efetivamente para sua governança, que vai além das tradições autoritárias e exploradoras.

Por meio de uma prática política, realmente transformadora (FREIRE, 2014, p. 120) seremos capazes, coletivamente de fazer da Escola do Campo uma opção de transformação de espaço ideário de sujeitos rurais para camponeses, no ermo "sertão" ao vivo, agradável, acolhedor, moderno e cultural Campo, um lugar onde os(as) jovens possam escolher viver ou não, de maneira libertária. 
BRASIL. Lei no 4504, de 30 de novembro de 1964. Estatuto da Terra. Brasilia.

BREDA, Laura Thumé. Estudo dos Impactos do Valor Recuperável de Ativos na Contabilidade de Empresas Siderúrgicas. O Caso da Crise nos Mercados Financeiros em 2008. 2008. 80 f. TCC (Graduação) - Curso de Administração, Ufrgs, Porto Alegre, 2008.

CARVALHO, Raquel Alves de. Identidade e Cultura dos Povos do Campo: entre preconceitos e resistências, qual o papel da educação? Curitiba: Appris, 2016.

CASTRO, Elisa Guaraná de. Os jovens estão indo embora: juventude rural e a construção de um ator político. Rio de Janeiro: Edur, 2009.

COELHO, Fabiano. É preciso fazer mística: o forjar de uma identidade coletiva sem terra. Dimensões, Vitória, v. 26, p. 325-349, 2011.

FREIRE, Paulo. Política e Educação. São Paulo: Paz e Terra, 2014.

LAZZARIN, Luiz Fernando. A dimensão multicultural da nova filosofia da educação musical. Abem, Porto Alegre, v. 14, p. 125-131, 2006.

MATEIRO, Teresa; ILARI, Beatriz. Pedagogias em Educação Musical. Curitiba: Ibpex, 2011.

MOREIRA, Jairto Saraiva. Professores do Assentamento Taquaral: A trajetória de luta pela terra e educação. 2010. 133 f. Dissertação (Mestrado) - Curso de Mestrado em Educação, UCDB, Campo Grande, 2010.

MUNARIN, Antônio; SHMIDIT, Wilson; PEIXER, Zilma Isabel. Educação do Campo: Políticas e Práticas em Santa Catarina. São Paulo: Outras Expressões, 2016

QUEIROZ, Luiz Ricardo da Silva. Música na escola: aspectos históricos da legislação nacional e perspectivas atuais a partir da Lei 11.769/2008. ABEM, Londrina, v. 20, n. 29, p. 23-38, 2008.

SOUZA, Jussamara. Aprender e ensinar música no cotidiano. 2. ed. Porto Alegre: Sulina, 2016. 